
Xing-Hai Liu',2*

\title{
Crystal structure and molecular docking studies of new pyrazole-4-carboxamides
}

https://doi.org/10.1515/hc-2019-0012

Received September 5, 2018; accepted January 31, 2019.

Abstract: Two pyrazol-4-carboxamides, 3-(difluoromethyl)$\mathrm{N}$-(mesitylcarbamoyl)-1-methyl-1H-pyrazole-4-carboxamide (7a) and 3-(difluoromethyl)-N-((3,5-dimethylphenyl) carbamoyl)-1-methyl-1 $\mathrm{H}$-pyrazole-4-carboxamide (7b) were synthesized and their structures were confirmed by the aid of ${ }^{1} \mathrm{H}$ NMR and HRMS analyses. The structure of the pyrazole-4-carboxamide, 7a was also determined by X-ray diffraction. The preliminary activity results demonstrate that these two compounds exhibit good inhibitory activity against Botrytis cinerea. Further docking results indicated that the key active group is difluoromethyl pyrazole moiety.

Keywords: pyrazole; urea; synthesis; crystal structure; docking

\section{Introduction}

Heterocyclic compounds received important attention due to their wide range of biological activities [1-5]. Many pyrazole carboxamide compounds had been developed as commercial fungicides targeting succinate dehydrogenase inhibitors (SDHIs), including penthiopyrad, sedaxane, pydiflumetofen, bixafen, fluxapyroxad, isopyrazam and benzovindiflupyr. In addition, pyrazole derivatives displayed diversity activities, such as antimicrobial [6], DPPH radical scavenging [7], anticancer activity [8], antifungal $[9,10]$, anti-inflammatory [11], nematicidal [12-19]

\footnotetext{
* Corresponding author: Xing-Hai Liu, College of Chemical Engineering, Zhejiang University of Technology, Hangzhou, 310014, Zhejiang, China; Key Laboratory of Green Pesticide and Agricultural Bioengineering, Ministry of Education, Guizhou University, Guiyang 550025, China

Li Qiao, Peng-Peng Cai, Zhong-Hua Shen, Hong-Ke Wu, Cheng-Xia Tan and Jian-Quan Weng, College of Chemical Engineering, Zhejiang University of Technology, Hangzhou, 310014, Zhejiang, China
}

and cholinesterases inhibitory activity [20]. On the other hand, urea group is always important key building block in many drugs or pesticides. The compounds with urea group exhibited diversity bioactivities, such as mosquito [21], antimicrobial [22], antiviral [23], antifungal [24-26] and antinociceptive activity [27].

In view of these facts mentioned above, and also as a part of our work on the synthesis of bioactive lead compounds for drug discovery [28-46], two new pyrazole-4-carboxamides, 3-(difluoromethyl)- $N$ (mesitylcarbamoyl)-1-methyl-1H-pyrazole-4-carboxamide (7a) and 3-(difluoromethyl)- $N$-((3,5-dimethylphenyl) carbamoyl)-1-methyl-1 $\mathrm{H}$-pyrazole-4-carboxamide $(7 \mathbf{b})$ were designed and synthesized. The structures were characterized by the aid of ${ }^{1} \mathrm{H}$ NMR and HRMS analysis. The single crystal structure of compound 7a was determined by X-ray diffraction. The fungicidal activity of these compounds was tested and the docking studies were also carried out to study the mode of action.

\section{Results and discussion}

\section{Synthesis}

The synthetic route of 3-(difluoromethyl)- $N$-(mesitylcarbamoyl)-1-methyl-1H-pyrazole-4-carboxamide is outlined in Scheme 1. In this paper, ethyl-2-(ethoxymethylene)4,4-difluoro-3-oxobutanoate and triethyl orthoformate took place smoothly in the presence of acetic anhydride resulted in the formation of intermediate $\mathbf{1}[47]$. Then the pyrazole ring was prepared by reacting intermediate $\mathbf{1}$ with methylhydrazine[48]. The pyrazole ester hydrosis under $\mathrm{NaOH}$ condition, then acid by $\mathrm{HCl}[49]$. The pyrazole acyl chloride was given using the $\mathrm{SOCl}_{2}$ as chlorinate reagent[50]. Then the pyrazole acyl chloride reacted with $\mathrm{NH}_{3} \bullet \mathrm{H}_{2} \mathrm{O}$ to give pyrazole amide[50]. The key intermediate pyrazole isocyanate was prepared by pyrazole amide and triphosgene[50]. Finally, the key intermediate pyrazole isocyanate reacted with 2,4,6-trimethylaniline and

O Open Access. (๑) 2019 Li Qiao et al., published by De Gruyter. @ T This work is licensed under the Creative Commons Attribution alone 4.0 License. 


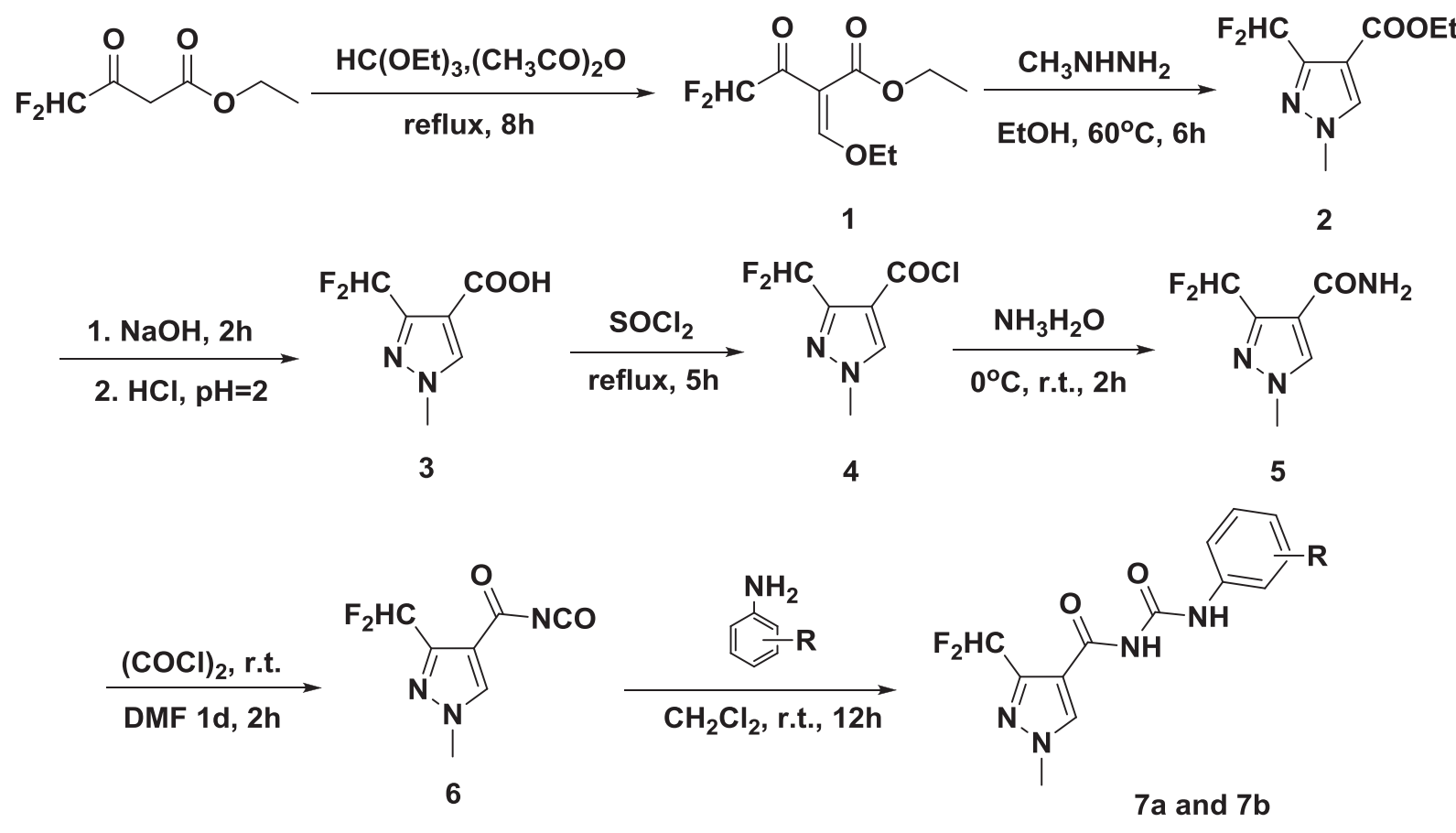

$7 a: R=2,4,6-3 M e ; 7 b: R=3,5-2 M e$

Scheme 1 The synthetic route of title compounds

3,5-dimethylaniline at room temperature. The reaction condition is mild.

The structures of the pure compounds $7 \mathbf{a}$ and $\mathbf{7 b}$ were confirmed by ${ }^{1} \mathrm{H}$ NMR, and HR MS. From the ${ }^{1} \mathrm{H}$ NMR data of compound $7 \mathrm{a}$, the signals at 2.28 and $2.31 \mathrm{ppm}$ were recognized as three methyl group of benzene ring. The appearance of signal at $3.92 \mathrm{ppm}$ belongs to the methyl protons of pyrazole ring. The two $\mathrm{NH}$ protons of urea bridge are found at 10.04 and $10.86 \mathrm{ppm}$ as single peak. The $\mathrm{CHF}_{2}$ proton signals were triple peak with the coupling constant $54 \mathrm{~Hz}$ due to the influence of $\mathrm{F}$ atom. The high resolution mass spectroscopies of the two compounds are in agreement with their molecular formula $\mathrm{C}_{16} \mathrm{H}_{18} \mathrm{~F}_{2} \mathrm{~N}_{4} \mathrm{O}_{2}(7 \mathbf{a})$ and $\mathrm{C}_{15} \mathrm{H}_{16} \mathrm{~F}_{2} \mathrm{~N}_{4} \mathrm{O}_{2}(7 \mathbf{b})$.

\section{Crystal structure}

The crystal belongs to triclinic system with space group $P-1$. The molecular structure of compound $7 \mathbf{a}$ is shown in Fig. 1, and the packing diagram in Fig. 2. The selected bond lengths and torsion angles are listed in Table $\mathbf{1}$.

Fig.1 View of the title compound 7a, with displacement ellipsoids drawn at the 30\% probability level.

Generally, the average bond lengths and bond angles of pyrazole ring and phenyl ring were normal ranges. The N2-C4 [1.346(3) Å], N1-C2 [1.336(3) Å] bond were longer than the general $\mathrm{C}=\mathrm{N}$ double bond length of 1.27 $\AA$, which indicated significant electron delocalization in the fused ring system. The torsion angle of C7-N3-C6-C3 and C8-N4-C7-N3 was -175.7(2) ${ }^{\circ}$ and $-179.4(2)^{\circ}$ respectively, which indicated the two carbonyl groups are opposite. The angle between the pyrazole ring and benzene ring is 68.2 ․

In the intermolecular edge-to-face $\pi-\pi$ stacking pattern of the title compound, it is worth mention that the two molecules of each stacking unit are cetrosymmetric, which can be proved by the relative position of the phenyl rings $(\mathrm{C} 8, \mathrm{C} 9, \mathrm{C} 10, \mathrm{C} 11, \mathrm{C} 12, \mathrm{C} 13)$ and methyl of pyrazole: the centroid separation of them is $3.131 \AA$. These interactions are estimated to play a role in stabilizing the crystal structure. The title compound $7 \mathbf{a}$ has an extensive network of hydrogen bonding. The parameters of intramolecular and intermolecular bonds are given in Table 2. From Fig. 1, the N(4)-H(4)...O(1) hydrogen bond formed a six member ring in the molecule. In the ac plane, they are linked together by N(3)$\mathrm{H}(3) \ldots \mathrm{O}(2)$ hydrogen bonds. This hydrogen-bonding sequence is repeated to form a ring. The ring is shaped like a decagon and has two $\mathrm{N}(4)$ and two $\mathrm{O}(1)$ atoms at the vertices, leading to a hydrogen-bond network defining cyclic motifs denoted $R_{2}^{2}(8)$. The hydrogen bonds and weak $\pi-\pi$ interactions strengthen the integration of the $3 D$ networks. 


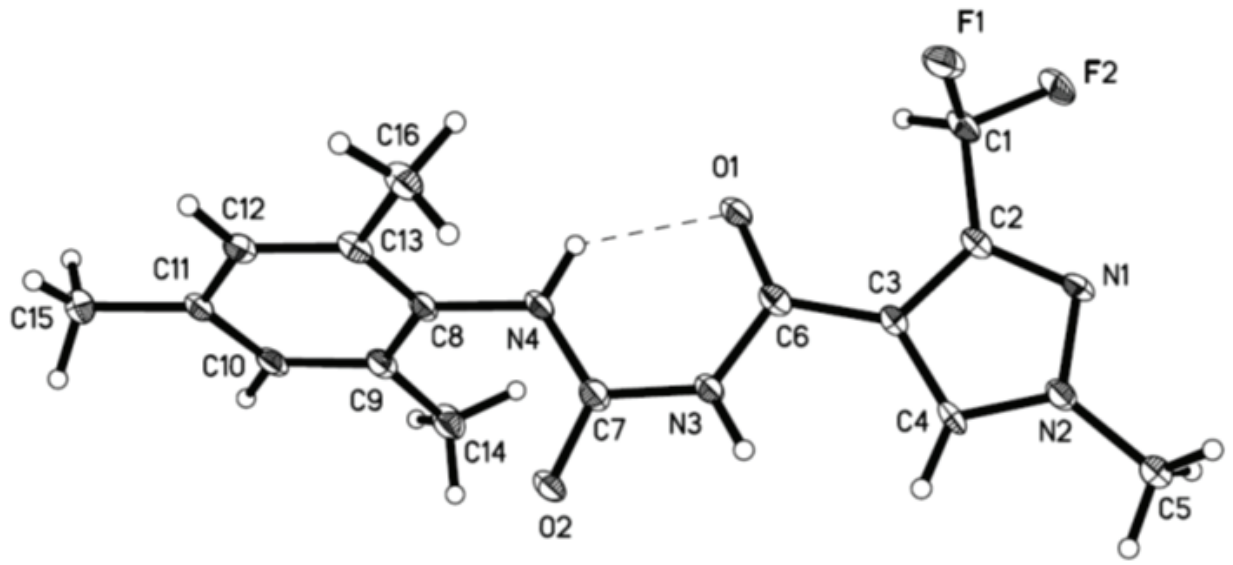

Figure 1 View of the title compound 7a, with displacement ellipsoids drawn at the 30\% probability level.

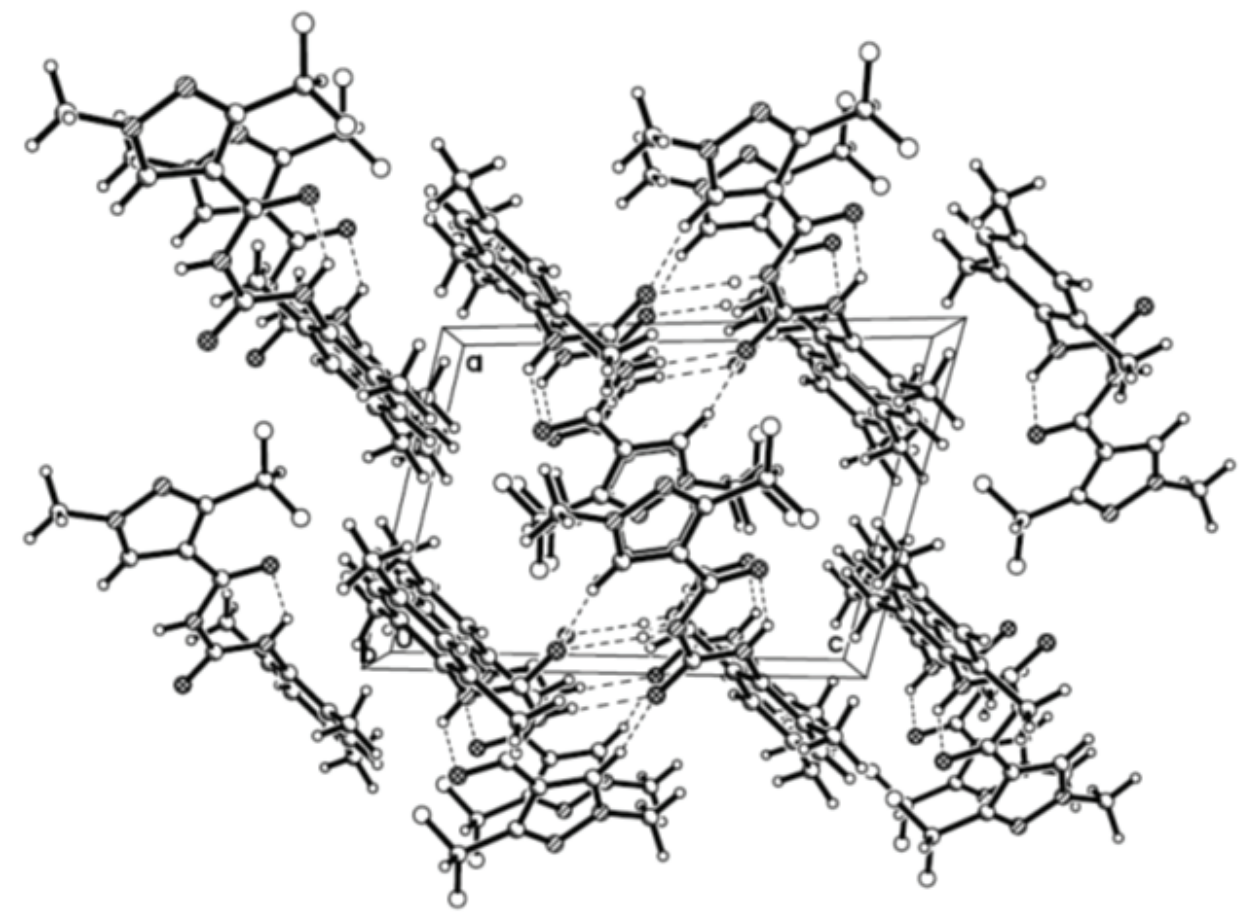

Figure 2 A view of pack molecule $7 a$.

\section{Evaluation of fungicidal activity}

Fungicidal activity of compounds $\mathbf{7 a}$ and $\mathbf{7 b}$ against Fusarium oxysporum, Corynespora mazei, Pseudomonas syringae and Botrytis cinerea was evaluated at $50 \mu \mathrm{g} / \mathrm{mL}$ according to our previous work [9, 42], Fluxapyroxad was used as controls and the results are listed in Table 3. The primary bioassay showed the two compounds exhibits good inhibiting activity $(60.00 \%$ and $77.27 \%)$ towards Botrytis cinere, which is the same as control (67.27\%). For the other three fungals Fusarium oxysporum, Corynespora mazei, Pseudomonas syringae, they exhibited weak activity with inhibitory $-49.20 \%$ and $-55.59 \%, 19.13 \%$ and $0.43 \%,-14.77 \%$ and $6.09 \%$ at $50 \mu \mathrm{g} / \mathrm{mL}$, respectively.

\section{Docking study}

In order to study the action mode of high active compound and the target, the binding modes between SDH (PDB:2FBW) and the active compound 7a were selected 
as exemplified in the case of representative compound by using the Discovery studio. The compound 7a can tightly occupy binding site of SDH, the docking results are shown in Figure 3. From the docking results, the compound 7a held two weak interactions: $\pi$-cation and $\pi$-sigma. The $\pi$-cation bond was formed between the pyrazole ring and Arg 43 amino acid residue with the distance of $4.1821 \AA$. The other $\pi$-sigma bond was formed between the pyrazole ring and Ile 218 amino acid residue with the distance of $2.82714 \AA$. The results indicated that the key active group is difluoromethyl pyrazole moiety.

\section{Experimental}

\section{Instruments}

Melting points were determined by an X-4 apparatus and uncorrected. ${ }^{1} \mathrm{H}$ NMR spectra were measured on a Bruker $\mathrm{AV}-400$ or $500 \mathrm{MHz}$ instrument using TMS as an internal standard and $\mathrm{CDCl}_{3}$ or DMSO- $d_{6}$ as the solvent. High

Table 1 Selected Bond lengths ( $(\AA)$, Selected Bond angles $\left(^{\circ}\right)$ for Compound 7a.

\begin{tabular}{lccc}
\hline Bond & Dist. & Angle & ( $^{\circ}$ \\
\hline $\mathrm{F}(1)-\mathrm{C}(1)$ & $1.376(3)$ & $\mathrm{C}(2)-\mathrm{N}(1)-\mathrm{N}(2)$ & $104.4(2)$ \\
$\mathrm{F}(2)-\mathrm{C}(1)$ & $1.363(3)$ & $\mathrm{C}(4)-\mathrm{N}(2)-\mathrm{N}(1)$ & $112.6(2)$ \\
$\mathrm{N}(1)-\mathrm{N}(2)$ & $1.360(3)$ & $\mathrm{C}(4)-\mathrm{N}(2)-\mathrm{C}(5)$ & $127.2(2)$ \\
$\mathrm{O}(1)-\mathrm{C}(6)$ & $1.232(3)$ & $\mathrm{N}(1)-\mathrm{N}(2)-\mathrm{C}(5)$ & $120.2(2)$ \\
$\mathrm{O}(2)-\mathrm{C}(7)$ & $1.242(3)$ & $\mathrm{C}(6)-\mathrm{N}(3)-\mathrm{C}(7)$ & $127.8(2)$ \\
$\mathrm{N}(1)-\mathrm{C}(2)$ & $1.336(3)$ & $\mathrm{C}(7)-\mathrm{N}(4)-\mathrm{C}(8)$ & $121.7(2)$ \\
$\mathrm{N}(3)-\mathrm{C}(7)$ & $1.391(3)$ & $\mathrm{F}(2)-\mathrm{C}(1)-\mathrm{F}(1)$ & $105.7(2)$ \\
$\mathrm{N}(2)-\mathrm{C}(4)$ & $1.346(3)$ & $\mathrm{N}(1)-\mathrm{C}(2)-\mathrm{C}(1)$ & $120.0(2)$ \\
$\mathrm{N}(4)-\mathrm{C}(7)$ & $1.345(3)$ & $\mathrm{C}(3)-\mathrm{C}(2)-\mathrm{C}(1)$ & $128.3(2)$ \\
$\mathrm{C}(1)-\mathrm{C}(2)$ & $1.494(4)$ & $\mathrm{N}(3)-\mathrm{C}(6)-\mathrm{C}(3)$ & $115.2(2)$ \\
$\mathrm{C}(2)-\mathrm{C}(3)$ & $1.424(4)$ & $\mathrm{N}(4)-\mathrm{C}(7)-\mathrm{N}(3)$ & $119.1(2)$ \\
\hline
\end{tabular}

Table 2 Hydrogen-bond Parameters (Á) of Compound 7a

\begin{tabular}{lllll}
\hline D-H...A & $\mathrm{d}(\mathrm{D}-\mathrm{H})$ & $\mathrm{d}(\mathrm{H} . . . A)$ & $\mathrm{d}(\mathrm{D} \ldots \mathrm{.A})$ & $\angle$ (DHA) \\
\hline $\mathrm{N}(3)-\mathrm{H}(3) \ldots \mathrm{O}(2) \#$ & 0.88 & 2.03 & $2.693(5)$ & 130.8 \\
$\mathrm{~N}(4)-\mathrm{H}(4) \ldots \mathrm{O}(1)$ & 0.88 & 1.98 & $2.830(6)$ & 161.6 \\
\hline
\end{tabular}

Symmetry transformations used to generate equivalent atoms: \#-1$X,-Y,-Z$ resolution mass spectra were recorded on an Agilent LCQ-TOF-MS 6520 instrument. Crystallographic data of the compound were collected on a Bruker APEX-II CCD diffractometer. All the reagents are of analytical grade or freshly prepared before use.

\section{General procedure}

The intermediates $\mathbf{1 , 2}, \mathbf{3}, \mathbf{4}, \mathbf{5}$ and $\mathbf{6}$ were synthesized according to our previous work [42]. A $10 \mathrm{~mL}$ round bottom flask was charged with 3-(difluoromethyl)-1-methyl-1H-pyrazole-4-carbonyl isocyanate 6 (201 $\mathrm{mg}, 1 \mathrm{mmol})$ and 2,4,6-trimethylaniline (135 mg, $1 \mathrm{mmol}$ ) in $\mathrm{CH}_{2} \mathrm{Cl}_{2}(4 \mathrm{~mL})$. The mixture was stirred at room temperature for overnight and the correspondence product was given. The target compounds were filtered and crude solids were recrystallized from ethanol to give the compound 7a. White solid, yield $66.7 \%$, $224.2 \mathrm{mg}$, m.p. $247 \sim 248{ }^{\circ} \mathrm{C}$, ${ }^{1} \mathrm{H}$ NMR ( 500 $\left.\mathrm{MHz}, \mathrm{CDCl}_{3}\right)$ 8: $2.28\left(\mathrm{~s}, 6 \mathrm{H}, 2 \mathrm{CH}_{3}\right), 2.31\left(\mathrm{~s}, 3 \mathrm{H}, \mathrm{CH}_{3}\right), 3.62$ (s, 3H, $\left.\mathrm{CH}_{3}\right), 6.85$ (t, J = $\left.54 \mathrm{~Hz}, 1 \mathrm{H}, \mathrm{CHF}_{2}\right), 6.97(\mathrm{~m}, 2 \mathrm{H}, \mathrm{Ar})$, 8.35 (s, 1H, CH), 10.04 (s, 1H, NH), 10.86 (s, 1H, NH); HRMS (ESI) for $\mathrm{C}_{16} \mathrm{H}_{18} \mathrm{~F}_{2} \mathrm{~N}_{4} \mathrm{O}_{2} \mathrm{~m} / z$ : Calculated, 337.1471, Found,

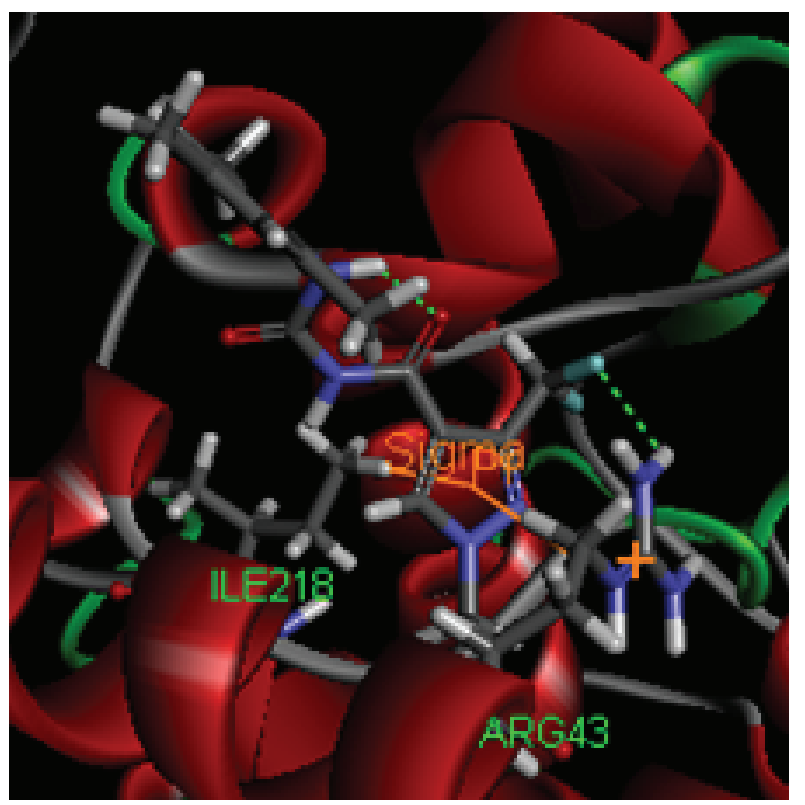

Figure 3 The docking mode of compound $7 \mathrm{a}$ and the SDH

Table 3 The fungicidal activity of compounds $7 \mathrm{a}$ and $7 \mathrm{~b}$ against four fungus at $50 \mathrm{mg} / \mathrm{L}$

\begin{tabular}{llcccc}
\hline No & R & Corynespora mazei & Pseudomonas syringae & Fusarium oxysporum & Botrytis cinerea \\
\hline 7a & $2,4,6-3 M e$ & -49.20 & 19.13 & -14.77 & 60.00 \\
7b & 3,5-2Me & -55.59 & 0.43 & 6.09 & 77.27 \\
Control & Fluxapyroxad & 74.09 & 52.55 & 71.301 & 67.27 \\
CK & water & 0 & 0 & 0 & 0 \\
\hline
\end{tabular}


$337.1470[\mathrm{M}+\mathrm{H}]^{+}$. The compound $\mathbf{7 b}$ was synthesized according to this method. 3-(difluoromethyl)- $N$-((3,5-dimethylphenyl)carbamoyl)-1-methyl-1 $\mathrm{H}$-pyrazole-4-carboxamide 7b :White solid, yield 53.5\%, 172.3 mg, m.p. $207 \sim 208{ }^{\circ} \mathrm{C}$, ${ }^{1} \mathrm{H}$ NMR ( $500 \mathrm{MHz}$, DMSO- $d_{6}$ ) $\delta: 2.35$ (s, 6H, $2 \mathrm{CH}_{3}$ ), 3.85 (s, 3H, $\left.\mathrm{CH}_{3}\right), 6.85$ (s, 1H, Ar), $7.14\left(\mathrm{t}, J=54 \mathrm{~Hz}, 1 \mathrm{H}, \mathrm{CHF}_{2}\right.$ ), 7.19 (s, 2H, Ar), 8.39 (s, 1H, CH), 9.89 (s, 1H, NH), 10.69 (s, 1H, NH); HRMS (ESI) for $\mathrm{C}_{15} \mathrm{H}_{16} \mathrm{~F}_{2} \mathrm{~N}_{4} \mathrm{O}_{2} \mathrm{~m} / z$ : Calculated, 323.1314, Found, $323.1314[\mathrm{M}+\mathrm{H}]^{+}$.

\section{Structure determination}

The cube-shaped single crystal of compound 7a was obtained by recrystallization from EtOH. The crystal with dimensions of $0.20 \mathrm{~mm} \times 0.18 \mathrm{~mm} \times 0.08 \mathrm{~mm}$ was mounted on a Rigaku Saturn diffractometer with a graphite-monochromated MoK $\alpha$ radiation $(\lambda=0.71073 \AA$ ) by using a Phi scan mode at $110(2) \mathrm{K}$ in the range of $3.646 \leq \theta \leq 55.758^{\circ}$. A total of 9797 reflections were collected, of which 3892 were independent $\left(R_{\text {int }}=0.0813\right)$ and 2075 were observed with $I>2 \sigma(I)$. The calculations were performed with SHELXS-97 program [51] and the empirical absorption corrections were applied to all intensity data. The nonhydrogen atoms were refined anisotropically. The hydrogen atoms were determined with theoretical calculations and refined isotropically. Crystal data for title compound: triclinic system, $P-1$ space group with $a=8.426(9) \AA, b=$ 9.149(9) $\AA, c=12.406(16) \AA, \alpha=68.374(11)^{\circ}, \beta=71.393(15)^{\circ}$, $y=74.816(11)^{\circ}, V=831.3(16) \AA^{3}, Z=2, T=110(2) \mathrm{K}$, $\mu(\mathrm{MoK} \alpha)=0.106 \mathrm{~mm}^{-1}$, Dcalc $=1.344 \mathrm{~g} / \mathrm{cm}^{3}, \mu(\mathrm{MoKa})=$ $0.106 \mathrm{~mm}^{-1}, \mathrm{GOOF}=0.973$. The final full-matrix leastsquares refinement gave $R=0.0654$ and $w R=0.1429$.

\section{Docking studies}

Molecular docking studies were done using Discovery Studio 2.5 software. The binding sites were generated from the SDH structure (PDB code: 2FBW) [12-19]. At first, water molecules were removed from the complex. Then, the crystallographic disorders and unfilled valence atoms were corrected using protein report and utility and clean protein options. Protein energy was minimized by applying CHARMM and MMFF94 force fields. The rigid structure of protein was obtained by applying fixed atom constraint. The protein binding site was defined and prepared for docking process. The structure of compound 7a was drawn using Discovery Studio 2.5 and minimized by applying CHARMM force field. Then, the minimized structures were prepared for docking using prepare ligand protocol. Docking process was carried out using
CDOCKER protocol. CDOCKER is a grid-based molecular docking method that employs CHARMM-based molecular dynamics (MD) scheme to dock ligands into a receptor binding site. The receptor was held rigid while the ligands were allowed to be flexible during the refinement. Each molecule was allowed to produce ten different interaction poses with the protein. Then, docking scores (-CDOCKER interaction energy) of the best-fitted poses with the active site at the SDH structure were recorded.

\section{Conclusion}

In summary, two new pyrazole-4-carboxamides, had been synthesized by multi-step reaction and characterized by ${ }^{1} \mathrm{H}$ NMR, HRMS and single-crystal X-ray structure determination. The results show that the crystal structure exhibits intermolecular and intramolecular hydrogen bonds. The fungicidal activity results showed that it possessed moderate activity against Botrytis cinerea. The docking results indicated the key active group is difluoromethyl pyrazole moiety.

Acknowledgement: This work was funded by Zhejiang Provincial Natural Science Foundation of China (No. LY19C140002), Research Fund of Department of Education of Zhejiang Province(Y201840646) and the Opening Foundation of the Key Laboratory of Green Pesticide and Agricultural Bioengineering, Ministry of Education, Guizhou University, grant No. 2018GDGP0104.

\section{References}

[1] Liu, X.H.; Tan, C.X.; Weng, J.Q. Synthesis, dimeric crystal, and fungicidal activity of 1- (4-methylphenyl)-2-(5-((3,5-dimethyl$1 H$-pyrazol-1-yl)methyl)-4-phenyl-4H-1,2,4-triazol-3-ylthio) ethanone, Phosphorus Sulfur Silicon Relat. Elem. 2011, 186, 558-564.

[2] Liu, X.H.; Pan, L.; Ma, Y.; Weng, J.Q.; Tan, C.X.; Li, Y.H.; Shi, Y.X.; Li, B.J.; Li, Z.M.; Zhang, Y.G. Design, synthesis, biological activities, and 3D-QSAR of new $N, N$ '-diacylhydrazines containing 2-(2,4-dichlorophenoxy)propane moiety. Chem. Biol. Drug Des. 2011, 78, 689-694.

[3] Yan, S.L.; Yang, M.Y.; Sun, Z.H.; Min, L.J.; Tan, C.X.; Weng, J.Q.; Wu, H.K.; Liu, X.H. Synthesis and antifungal activity of 1,2,3-thiadiazole derivatives containing 1,3,4-thiadiazole moiety. Lett. Drug Des. Discov. 2014, 11, 940-943.

[4] Zhai, Z.W.; Shi, Y.X.; Yang, M.Y.; Zhao W.; Sun Z.H.; Weng J.Q.; Tan C.X.; Liu X.H.; Li B.J.; Zhang Y.G. Microwave assisted synthesis and antifungal activity of some novel thioethers containing 1,2,4-triazolo[4,3-a]pyridine moiety. Lett. Drug Des. Discov. 2016, 13, 521-525. 
[5] Liu, X.H.; Tan, C.X.; Weng, J.Q. Phase transfer-catalyzed, one-pot synthesis of some novel $N$-pyrimidinyl- $N$ '-nicotinyl thiourea derivatives, Phosphorus Sulfur Silicon Relat. Elem. 2011, 186, 552-557.

[6] Padalkar, V.S.; Borse, B.N.; Gupta, V.D.; Phatangare, K.R.; Patil, V.S.; Sekar, N. Synthesis and antimicrobial activities of novel 2-[substituted-1H-pyrazol-4-yl] benzothiazoles, benzoxazoles, and benzimidazoles. J. Heterocycl. Chem. 2016, 53, 1347-1355.

[7] Radi, S.; Attayibat, A.; El-Massaoudi, M.; Salhi, A.; Eddike, D.; Tillard, M.; Mabkhot, Y.N. X-ray single crystal structure, DFT calculations and biological activity of 2-(3-methyl-5-(pyridin-2 '-yl)-1H-pyrazol-1-yl) ethanol. Molecules 2017, 21, 1020.

[8] Gomha, S.M.; Abdel-aziz, H.M.; El-Reedy, A.A.M. Facile Synthesis of pyrazolo[3,4-c]pyrazoles bearing coumarine ring as anticancer agents. J. Heterocycl. Chem. 2018, 55, 1960-1965.

[9] Wang, H.; Zhai, Z.W.; Shi, Y.X.; Tan, C.X.; Weng, J.Q.; Han, L.; Li, B.J.; Liu, X.H. Novel trifluoromethylpyrazole acyl thiourea derivatives: synthesis, antifungal activity and docking study. Lett Drug Des Discov 2018, published ahead of print; doi: 10.2174/1570180815666180704103047.

[10] Mu, J.X.; Shi, Y.X.; Yang, M.Y.; Sun, Z.H.; Liu, X.H.; Li, B.J.; Sun, N.B. Design, synthesis, DFT study and antifungal activity of pyrazolecarboxamide derivatives. Molecules, 2016, 21, 68.

[11] Kumbar, M.N.; Kamble, R.R.; Dasappa, J.P.; Bayannavar, P.K.; Khamees, H.A.; Mahendra, M.; Joshi, S.D.; Dodamani, S.; Rasal, V.P.; Jalalpure, S. 5-(1-Aryl-3-(thiophen-2-yl)-1H-pyrazo14-yl)-1H-tetrazoles: synthesis, structural characterization, hirshfeld analysis, anti-inflammatory and anti-bacterial studies. J. Mol. Struct. 2018, 1160, 63-72.

[12] Zhao, W.; Shen, Z.H.; Xu, T.M.; Peng, W.L.; Liu, X.H. Synthesis and nematocidal activity of novel pyrazole carboxamide derivatives against Meloidogyne incognita. Lett. Drug Des. Discov. 2017, 14, 323-329.

[13] Zhao, W.; Shen, Z.H.; Xing, J.H.; Xu, T.M.; Peng, W.L.; Liu, X.H. Synthesis, characterization, nematocidal activity and docking Study of novel pyrazole-4-carboxamide derivatives. Chin. J. Struct. Chem. 2017, 36, 423-428.

[14] Liu, X.H.; Zhao, W.; Shen, Z.H.; Xing, J.H.; Xu, T.M.; Peng, W.L. Synthesis, nematocidal activity and SAR study of novel difluoromethylpyrazole carboxamide derivatives containing flexible alkyl chain moieties. Eur. J. Med. Chem. 2017, 125, 881-889.

[15] Cheng, L.; Zhao, W.; Shen, Z.H.; Xu, T.M.; Wu, H.K.; Peng, W.L.; Liu, X.H. Synthesis, nematocidal activity and docking study of novel pyrazole-4-carboxamide derivatives against meloidogyne incognita. Lett. Drug Des. Discov. 2019, 16, 29-35.

[16] Cheng, L.; Shen, Z.H.; Xu, T.M.; Tan, C.X.; Weng, J.Q.; Han, L.; Peng, W.L.; Liu. X.H. Synthesis and nematocidal activity of $\mathrm{N}$-substituted 3-methyl-1H-pyrazole-4-carboxamide derivatives against Meloidogyne incognita. J. Heterocycl. Chem. 2018, 55, 946-950.

[17] Zhao, W.; Xing, J.H.; Xu, T.M.; Peng, W.L.; Liu, X.H. Synthesis and in vivo nematocidal evaluation of novel 3-(trifluoromethyl)$1 \mathrm{H}$-pyrazole-4-carboxamide derivatives. Front. Chem. Sci. Eng. 2017, 11, 363-368.

[18] Zhao, W.; Shen, Z.H.; Xing, J.H.; Yang, G.; Xu, T.M.; Peng, W.L.; Liu, X.H. Synthesis and nematocidal activity of novel 1-(3-chloropyridin-2-yl)-3-(trifluoromethyl)-1H-pyrazole-4carboxamide derivatives. Chem. Pap. 2017, 71, 921-928.
[19] Liu, X.H.; Zhao, W.; Shen, Z.H.; Xing, J.H.; Yuan, J.; Yang, G.; Xu, T.M.; Peng, W.L. Synthesis, nematocidal activity and docking study of novel chiral 1-(3-chloropyridin-2-yl)3-(trifluoromethyl)-1H-pyrazole-4-carboxamide derivatives. Bioorg. Med. Chem. Lett. 2016, 26, 3626-3628.

[20] Derabli, C.; Boualia, I.; Abdelwahab, A.B.; Boulcina, R.; Bensouici, C.; Kirsch, G.; Debache, A. A cascade synthesis, in vitro cholinesterases inhibitory activity and docking studies of novel Tacrine-pyranopyrazole derivatives. Bioorg. Med. Chem. Lett. 2018, 28, 2481-2489.

[21] Fang, Y.M.; Zhang, R.R.; Shen, Z.H.; Tan, C.X.; Weng, J.Q.; Xu, T.M.; Liu, X.H. Huang, H.Y.; Wu, H.K. Synthesis and antifungal activity of some 6-tert-butyl-8-chloro-2, 3-dimethylquinolin4-ol derivatives against Pyricularia oryae. Lett. Drug Des. Discov. 2018, 15, 1314-1318.

[22] Venkatesh, T.; Bodke, Y.D.; Joy, M.N.; Dhananjaya, B.L.; Venkataraman, S. Synthesis of some benzofuran derivatives containing pyrimidine moiety as potent antimicrobial agents. Iran J. Pharm. Res. 2018, 17, 75-86.

[23] Huang, Y.Q.; Guo, Z.L.; Song, H.J.; Liu, Y.X.; Wang, L.Z.; Wang, Q.M. Design, Synthesis, and biological activity of beta-carboline analogues containing hydantoin, thiohydantoin, and urea moieties. J. Agr. Food Chem. 2018, 66, 8253-8261.

[24] Zhang, Z.J.; Zeng, Y.; Jiang, Z.Y.; Shu, B.S.; Sethuraman, V.; Zhong, G.H. Design, synthesis, fungicidal property and QSAR studies of novel-carbolines containing urea, benzoylthiourea and benzoylurea for the control of rice sheath blight. Pest Manag. Sci. 2018, 74, 1736-1746.

[25] Liu, X.H.; Wang, Q.; Sun, Z.H.; Wedge, D.E.; Becnel, J.J.; Estep, A.S.; Tan, C.X.; Weng, J.Q. Synthesis and insecticidal activity of novel pyrimidine derivatives containing urea pharmacophore against Aedes aegypti. Pest Manag. Sci. 2017, 73, 953-959.

[26] Jin, T.; Zhai, Z.W.; Han, L.; Weng, J.Q.;Tan, C.X.; Liu, X.H. Synthesis, crystal structure, docking and antifungal activity of a new pyrazole acylurea compound. Chin. J. Struct. Chem. 2018, 37, 1259-1264.

[27] Lopes, R.D.; Alves, M.A.; Pinheiro, R.O.; Freitas, C.S.; Cunha, F.Q.; Barreiro, E.J.; Lima, L.M. Synthesis, aqueous solubility, metabolic stability and pharmacological profile of simplified urea derivatives. Lett. Drug Des. Discov. 2018, 15, 766-777.

[28] Zhang, L.J.; Yang, M.Y.; Sun, Z.H.; Tan, C.X.; Weng, J.Q.; Wu, H.K.; Liu X.H. Synthesis and antifungal activity of 1,3,4-thiadiazole derivatives containing pyridine group. Lett. Drug Des. Discov. 2014, 11, 1107-1111.

[29] Shen, Z.H.; Sun, Z.H.; Becnel, J.J.; Estep, A.; Wedge, D.E.; Tan, C.X.; Weng, J.Q.; Han, L, Liu. X.H. Synthesis and mosquiticidal activity of novel hydrazone containing pyrimidine derivatives against Aedes aegypti. Lett. Drug Des. Discov. 2018, 15 , 951-956.

[30] Liu, X.H.; Fang, Y.M.; Xie, F.; Zhang, R.R.; Shen, Z.H.; Tan, C.X.; Weng, J.Q.; Xu, T.M.; Huang, H.Y., Synthesis and in vivo fungicidal activity of some new quinoline derivatives against rice blast. Pest Manag. Sci. 2017, 73, 1900-1907.

[31] Cheng, L.; Cai, P.P.; Zhang, R.R.; Han, L.; Tan, C.X.; Weng, J.Q. Xu, T.M.; Liu, X.H. Synthesis and biological activity of some new 6-perfluoropropanyl quinoline derivatives. J. Heterocycl. Chem. 2018, 55, 2585-2589.

[32] Cheng, L.; Cai, P.P.; Zhang, R.R.; Han, L.; Tan, C. X.; Weng, J. Q.; Xu, T. M.; Liu, X. H. Synthesis and Insecticidal Activity of New 
Quinoline Derivatives Containing Perfluoropropanyl Moiety. J. Heterocycl. Chem. 2019, 56, 1312-1317.

[33] Cheng, L.; Zhang, R.R.; Wu, H.K.; Xu, T.M.; Liu, X.H. The synthesis of 6-(tert-butyl)-8-fluoro-2,3-dimethylquinoline carbonate derivatives and their antifungal activity against pyricularia oryzae. Front. Chem. Sci. Eng. 2018, published ahead of print; doi:10.1007/s11705-018-1734-7.

[34] Liu, X.H.; Sun, Z.H.; Yang, M.Y.; Tan, C.X.; Weng, J.Q.; Zhang, Y.G.; Ma, Y. Microwave assistant one pot synthesis, crystal structure, antifungal activities and 3D-QSAR of novel 1,2,4-triazolo[4,3-a]pyridines. Chem. Biol. Drug Des. 2014, 84, 342-347

[35] Liu, X.H.; Xu, X.Y.; Tan, C.X.; Weng, J.Q.; Xin, J.H.; Chen, J. Synthesis, crystal structure, herbicidal activities and 3D-QSAR study of some novel 1,2,4-triazolo[4,3-a]pyridine derivatives, Pest Manag. Sci. 2015, 71, 292-301.

[36] Liu, X.H.; Zhai, Z.W.; Xu, X.Y.; Yang, M.Y.; Sun, Z.H.; Weng, J.Q.; Tan, C.X.; Chen, J. Facile and efficient synthesis and biological activity determination of novel 1,2,4-triazolo[4,3-a]pyridin$3(2 \mathrm{H})$-one derivatives via microwave irradiation. Bioorg. Med. Chem. Lett. 2015, 25, 5524-5528.

[37] Fang, Y.M.; Zhang, R.R.; Shen, Z.H.; Tan, C.X.; Weng, J.Q.; Xu, T.M.; Liu, X.H. Huang, H.Y.; Wu, H.K. Synthesis and antifungal activity of some 6-tert-butyl-8-chloro-2, 3-dimethylquinolin4-ol derivatives against Pyricularia oryae. Lett. Drug Des. Discov. 2018, 15, 1314-1318.

[38] Sun, N.B.; Zhai, Z.W.; Tong, J.Y.; Cai, P.P.; He, F.Y.; Han, L.; Liu, X.H. Synthesis, Crystal Structure and fungicidal activity of 3-(difluoromethyl)-1-methyl- $N$-((2-(trifluoromethyl)phenyl) carbamoyl)-1H-pyrazole-4-carboxamide. Chin. J. Struct. Chem. 2018, published ahead of print; doi: 10.14102/j.cnki.02545861.2011-2176.

[39] Sun, N.B.; Zhai, Z.W.; Shen, Z.H.; Weng, J.Q.; Tan, C.X.; Liu, X.H.; Han, L. Synthesis, crystal structure and antifungal activity of $\mathrm{N}$-((2,6-difluorophenyl)carbamoyl)1,3-dimethyl -1H-pyrazole4-carboxamide. Chin. J. Struct. Chem. 2017, 36, 1667-1672.

[40] Shen, Z.H.; Zhai, Z.W.; Sun, Z.H.; Weng, J.Q.; Tan, C.X.; Liu, X.H. Synthesis, crystal structure and biological activity of 2-chloro-5-((5-(1-methyl-3-(trifluoromethyl) -1H-pyrazol-4-yl)4-phenyl-4H-1,2,4-triazol-3-yl)thio)methyl)thiazole. Chin. J. Struct. Chem. 2017, 36, 1137-1141.
[41] Yang, M.Y.; Zhai, Z.W.; Sun, Z.H.; Yu, S.J.; Liu, X.H.; Weng, J.Q.; Tan, C.X.; Zhao, W.G. A facile one-pot synthesis of novel 1,2,4-triazolo[4,3-a]pyridine derivatives containing the trifluoromethyl moiety using microwave irradiation. J. Chem. Res. 2015, 9, 521-523.

[42] Zhai, Z.W.; Yang, M.Y.; Sun, Z.H.; Liu, X.H.; Weng, J.Q.; Tan, C.X. Facile and efficient synthesis of novel 1,2,3-thiadiazole derivatives using microwave irradiation. J. Chem. Res. 2015, 9, 340-342.

[43] Liu, X.H.; Pan, L.; Weng, J.Q.; Tan, C.X.; Li, Y.H.; Wang, B.L.; Li, Z.M. Synthesis, structure, and biological activity of novel (oxdi/ tri)azoles derivatives containing 1,2,3-thiadiazole or methyl moiety. Mol. Divers. 2012, 16, 251-260.

[44] Liu, X.H.; Pan, L.; Tan, C.X.; Weng, J.Q.; Wang, B.L.; Li, Z.M. Synthesis, crystal structure, bioactivity and DFT calculation of new oxime ester derivatives containing cyclopropane moiety. Pestic. Biochem. Physiol. 2011, 101, 143-147.

[45] Weng, J.Q.; Wang, L.; Liu, X.H. Synthesis, Crystal Structure and Herbicidal Activity of a 1, 2, 4-triazol-5(4H)-one Derivative. J. Chem. Soc. Pak. 2012, 34, 1248-1252.

[46] Liu, X.H.; Zhao, W.G.; Wang, B.L.; Li, Z.M. Synthesis, bioactivity and DFT structure-activity relationship study of novel 1,2,3-thiadiazole derivatives. Res. Chem. Intermed. 2012, 38, 1999-2008.

[47] Sun, N.B.; Shen, Z.H.; Zhai, Z.W.; Han, L.; Weng, J.Q.; Tan, C.X.; Liu, X.H. Design, Synthesis, Fungicidal Activity and Docking Study of Acyl Thiourea Derivatives Containing Pyrazole Moiety. Chin. J. Org. Chem. 2017, 37, 2705-2710.

[48] Ding, X.M.; Zhai, Z.W.; Lv, L.P.; Sun, Z.H.; Liu, X.H. Design, synthesis, biological activity and density function theory study of pyrazole derivatives containing 1,3,4-thiadiazole moiety. Front. Chem. Sci. Eng. 2017, 11, 379-386.

[49] Wang, H.; Zhai, Z.W.; Shi, Y.X.; Tan, C.X.; Weng, J.Q.; Han, L.; Li, B.J.; Liu, X.H. Novel trifluoromethylpyrazole acyl urea derivatives: Synthesis, crystal structure, fungicidal activity and docking study. J Mol Struct 2018, 1171, 631-638.

[50] Sun, N.B.; Shen, Z.H.; Zhai, Z.W.; Wu, H.K.; Weng, J.Q.; Tan, C.X.; Liu, X.H. Design, Synthesis, Fungicidal Activity and Docking Study of Acyl Urea Derivatives Containing Pyrazole Moiety. Chin. J. Org. Chem. 2017, 37, 2044-2049.

[51] Sheldrick, G. M. SHELXS97 and SHELXL97, University of Göttingen, Germany, 1997. 